\title{
The Fire Station as an Essential Tool in Urban Community Development: The Case of Chepo, Panama
}

\author{
Jeffrey S. Smith ${ }^{1}$, Jorge D. Coromac ${ }^{2}$, Victor Raul Alvarez ${ }^{3}$ \\ ${ }^{1}$ Department of Geography, Kansas State University, Manhattan, USA \\ ${ }^{2}$ Woodland Public Charities, Kansas City, USA \\ ${ }^{3}$ Fire Department for the Republic of Panama, Chepo, Panama \\ Email: jssmith7@ksu.edu
}

How to cite this paper: Smith, J. S., Coromac, J. D., \& Alvarez, V. R. (2016). The Fire Station as an Essential Tool in Urban Community Development: The Case of Chepo, Panama. Current Urban Studies, 4, 297-302. http://dx.doi.org/10.4236/cus.2016.43020

Received: August 17, 2016

Accepted: September 11, 2016

Published: September 14, 2016

Copyright $\odot 2016$ by authors and Scientific Research Publishing Inc. This work is licensed under the Creative Commons Attribution International License (CC BY 4.0).

http://creativecommons.org/licenses/by/4.0/ (c) (7) Open Access

\begin{abstract}
As the world's population becomes increasingly urban, efforts to improve the quality of life among the impoverished must turn to cities. The literature asserts that the most successful programs in the fight against poverty are those that are implemented and managed by local community members. Moreover, the personnel in charge of distributing aid must have: 1) the trust and confidence of the community, 2) experience with community outreach, 3) a record of disseminating useful information, and 4) a clear understanding of local cultural traditions. The fire department is an often overlooked community resource that fulfills these requirements. Within the city of Chepo, Panama the fire station has successfully by-passed the thick layers of bureaucracy and is effectively reaching the city's urban poor. Fire departments in other cities throughout the Global South might consider emulating the example set by Chepo.
\end{abstract}

\section{Keywords}

Urban Development, Global South, Fire Station, Chepo, Panama

\section{Introduction}

There are three germane facts about population and development in the Global South. First, the various efforts by the world community to combat extreme poverty (e.g. micro-loans, UN School Lunch Program, Conditional Cash Transfers) are starting to show results, albeit slowly. In 1990, the world's total population was 5.3 billion and 1.9 billion people were living on less than US $\$ 1$ per day. In 2015, the world's population 
reached 7.3 billion, yet there are fewer individuals ( 700 million) living in extreme poverty (Economist, 2015). Second, most of the aid and effort to combat global poverty is focused on rural areas. Although impoverished people in cities face the same challenges as their rural counterparts (e.g. food insecurity, inadequate housing, lack of basic infrastructure, insufficient education and health care services), "[U]rban poverty reduction is among the lowest priority for aid donations from most multilateral agencies." (Parsons, 2010: p. 50). Third, the proportion of the world's total population living in urban areas has steadily increased since the turn of the twentieth century. Increasing industrialization since the 1950s, combined with chronic rural poverty has led to sustained rural-to-urban migration (PRB, 2015; Dahlman, 2016). For the first time, in 2007, over 50 percent of the world's people were living in cities (PRB, 2007). By 2030 it is expected that more than 60 percent of the world's population will reside in urbanized areas and most of the growth will continue to occur in cities of the Global South. The locus for fighting global poverty needs to shift from rural areas to the cities (Parsons, 2010; Erokhin, 2014). How do we tackle this growing urban problem without sacrificing the gains we have achieved in rural areas? Lacking is an effective approach for reaching the world's marginalized population living in cities (Economist, 2015). The purpose of this field report is to articulate how the local fire station is a valuable community resource that can serve as an effective tool in reaching the urban poor.

\section{Background}

In the 1970s international aid organizations and national governments began serious campaigns to end extreme poverty worldwide (Shah, 2012; UN, 2014a). Over the past 45 years the most common approach to development in the Global South has been top-down funding schemes. Because this approach is mired with problems (Easterly, 2006; Smith et al., 2016), a growing number of scholars advocate for a bottom-up approach (Escobar, 1992; Brunt and McCourt, 2011) where local actors lead efforts to remedy local challenges. Regardless of which approach is taken, most endeavors to end poverty have been carried out in rural areas where examples are widespread and blatant.

Since the 1950s population growth in the world's rural areas has slowed considerably as fewer people engage in agricultural practices and cities siphon off pools of labor. As the rural population continues its protracted decline, the number of people living in cities is accelerating. Although poor living conditions in mega-cities receive most of the attention, only about 12 percent of the world's population lives in these cities of 10 million people or more. By comparison, nearly half of earth's urban population lives in cities with 500,000 people or less and they are host to the most rapid rate of population increase (UN, 2014b). Urbanization offers numerous potential benefits for residents (e.g. diverse employment opportunities, improved infrastructure, better education and health care), yet rapid, unplanned urban growth threatens sustainable development and places peoples' quality of life at risk (Erokhin, 2014; UN, 2014b; World Bank, 2016).

In 2015, the United Nations launched its newest 15-year plan (2030 Sustainable De- 
velopment Goals) to end world poverty (UN, 2015). Their seventeen goals range from eradicating global hunger and promoting gender equality to developing affordable energy and ensuring environmental protection. Showing a clear understanding of the trends in world urban growth, the UN included a specific goal to end poverty in urban areas by 2030. The UN declares that cities of all sizes should become sustainable, inclusive, and safe (UN, 2015), but the organization does not specify how the world community will engage the growing number of urban poor. The literature is replete with reminders that empowering locals is the key to successful rural development in the Global South (Crescenzi and Rodríguez-Pose, 2011). This is no less pertinent in urban areas. Assistance in cities is much more effective if responsibilities are delegated to local residents and the decision-making process is transferred to the local level (Parsons, 2010). Questions remain. What is an effective method of reaching impoverished people living in the cities of the Global South? Are there any existing community resources that can be expanded to reach the urban poor? To date there are few empirical examples illustrating the best practices of poverty outreach in urban areas. The remainder of this paper showcases how a local fire station is well-positioned to serve the needs of the urban poor.

\section{Chepo, Panama}

As part of a larger project that explores water resources within central Panama, this article draws upon field work conducted in the city of Chepo, Panama. Chepo was founded in 1569 as a critical gateway community for the Spanish as they expanded their zone of influence from Panama City into indigenous-held lands (McCarthy, 2013). Located along the Pan-American Highway, Chepo has long served as an important service city within central Panama; it is home to the region's only hospital and high school and is the seat of government for the Chepo district (Figure 1). According to the 2010

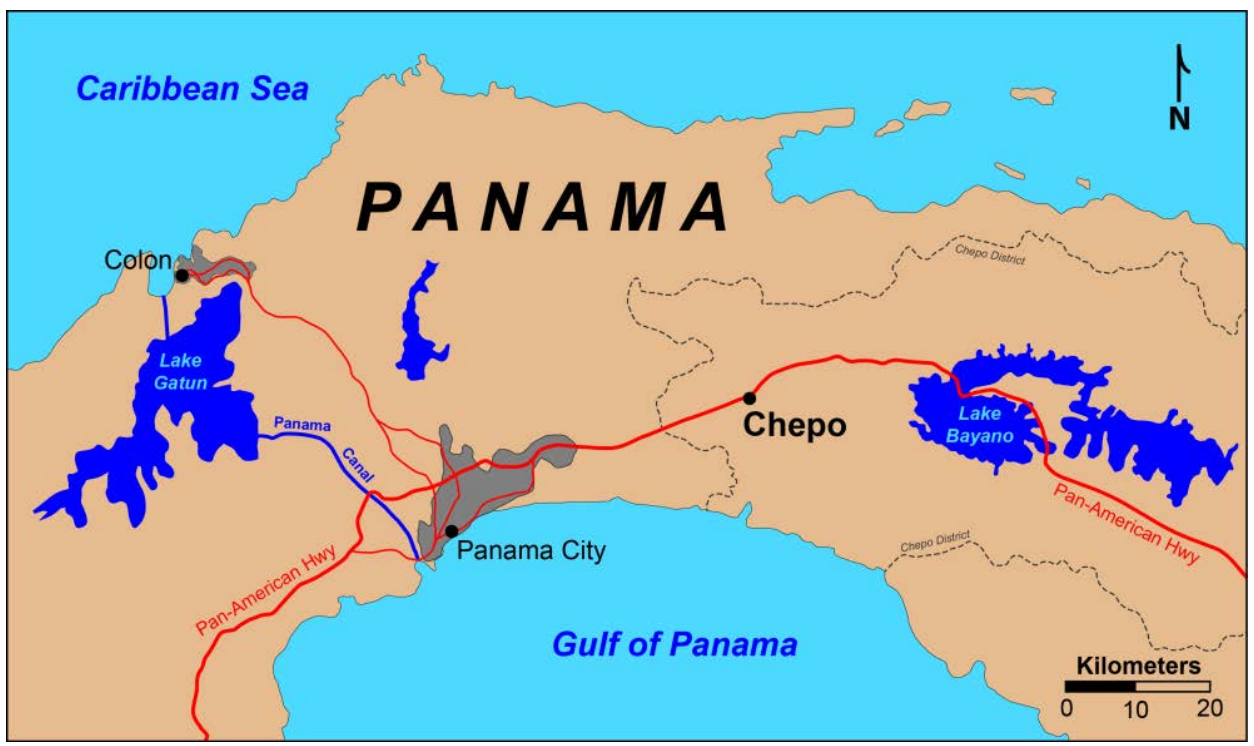

Figure 1. Map of Central Panama, including the city of Chepo. Cartography by Jeffrey S. Smith. 
Census, the city of Chepo proper has a total population of 20,420, yet the city serves as a central place for surrounding villages and homesteads numbering over 46,000 people (PPHC, 2010). Today, Chepo has become a bedroom community for many people who work in Panama City; its population is steadily increasing because it is the first step rural residents make as they leave the countryside searching for better employment opportunities in urban areas (especially Panama City).

\section{The Fire Station as a Tool in Community Development}

In cities throughout the Global South governmental agencies and non-governmental organizations (NGO) offer a multitude of community services to improve the quality of life for impoverished residents. Successful programs have managed to cut through thick layers of bureaucracy and directly reach people in need. In Chepo, Panama the local fire department demonstrates that fire fighting personnel are well-positioned to successfully provide services to the urban poor.

1) Having the public's trust and confidence is a key to offering relief aid. As public servants, first responders (e.g. paramedics, police, and firefighters) have distinct reputations within the community. Although police are deployed to serve and protect, the general public sees their primary role as enforcers of local laws and regulations. Because firefighters seek to ensure peoples' health and safety, they possess a more altruistic reputation-one that has earned them considerable confidence within the community. When fire department personnel reach out to the community with aid and assistance it is readily received because they are trusted within the community.

2) A second key to successful aid is experience with community outreach. Seeing firefighters standing in the road collecting food and money to help the poor is a common sight in cities around the world. Within Chepo firefighting personnel have a long tradition of collecting and distributing food and disability support devices (e.g. walkers, crutches, and wheelchairs) for residents in need. With assistance from a local politician and two NGOs the fire station in Chepo expanded its outreach by becoming a clearing house for the distribution of not only food and disability devices, but a wide variety of much-needed resources including beds and water purification filters. The fire department has become an essential community resource in the distribution of items that improve the quality of life for some of the poorest residents.

3) A third key to success is reputation for disseminating accurate, useful information. As is common in many parts of the world, the fire station in Chepo regularly offers clinics that seek to improve fire safety and awareness among local residents. Clearly, the fire department has a reputation for being the source of beneficial information. With assistance from an international NGO, it became an easy leap for the fire department to begin offering information about proper health and sanitation. First, the community bulletin board was used as a means to communicate warnings about immediate health and safety risks. Then, drawing upon their medical background as paramedics, the fire department personnel began offering classes to disadvantaged members of the community that focus on health and safety issues. These expanded services have greatly improved the lives of local residents. 
4) One of the most important keys in the successful distribution of relief aid is an understanding of the prevailing culture. When aid is offered in a manner that is compatible with local cultural tradition, the efforts are more fruitful. Because fire department personnel are permanent residents within the community, they know and understand the nuances of the local culture. This has proven to be particularly helpful within the city of Chepo and its surrounding area because there is a sizeable Kuna Indian population that practices distinct cultural traditions. The aid that firefighters offer is well received because it is distributed in a culturally appropriate manner.

\section{Conclusion}

In 2007, the world became predominantly urban when 50 percent of the total population was found living in cities. Every indication suggests that the global population will continue to become more urban with most of the growth unfolding in cities of the Global South. As the world community seeks to improve the quality of life for all individuals, the locus for fighting global poverty needs to shift from rural areas to the cities. As this article illustrates, the fire station is an often overlooked, yet effective resource that can be used to reach the urban poor. Fire fighting personnel have the trust and confidence of the community, they have demonstrated experience with community outreach, they have a record of disseminating useful information, and they possess a clear understanding of local cultural traditions. The fire station in Chepo, Panama has successfully by-passed the thick layers of bureaucracy and is effectively reaching the city's urban poor. The experience in Chepo is not isolated or unique, rather the practices followed in Chepo should be applicable to other cities in the Global South.

\section{References}

Brunt, C., \& McCourt, W. (2011). Do INGOs in Kenya Walk the Talk? Reconciling the "Two Participations" in International Development. http://eadi.org/gc2011/brunt-411.pdf

Crescenzi, R., \& Rodríguez-Pose, A. (2011). Reconciling Top-Down and Bottom-Up Development Policies. Environment and Planning A, 43, 773-780.

Dahlman, C. (2016). A New Paradigm for Rural Development. http://oecdinsights.org/2016/03/31/a-new-paradigm-for-rural-development/

Easterly, W. (2006). The White Man's Burden: Why the West's Efforts to Aid the Rest Have Done So Much Ill and So Little Good. Penguin Press: New York.

Economist. (2015). Extreme Poverty Leaving It Behind. 59-60.

Erokhin, V. (2014). Approaches to Sustainable Rural Development in a Predominantly Non-Rural Region. Economics of Agriculture, 61, 291-306.

Escobar, A. (1992). Reflections on Development: Grassroots Approaches and Alternative Politics in the Third World. Futures, 24, 411-436.

McCarthy, C. (2013). Panama. London: Lonely Planet.

Parsons, A. (2010). The Seven Myths of "Slums": Challenging Popular Prejudices about the World's Urban Poor. www.sharing.org/sites/default/files/images/PDFs/7_myths_report\%20(2).pdf

PPHC (Panama Population and Housing Census). (2010). Table 11. Population and Density for 
the Republic of Panama; Census 1990 to 2010. Panama: National Institute of Statistics and Census.

PRB (Population Reference Bureau). (2007). Urban Population to Become the New Majority Worldwide. www.prb.org/Publications/Articles/2007/UrbanPopToBecomeMajority.aspx

PRB (Population Reference Bureau). (2015). Urban and Rural Disparities Remain Despite Progress in Closing Health and Development Gaps. www.prb.org/Publications/Datasheets/2015/urban-rural-datasheet.aspx

Shah, A. (2012). Foreign Aid for Development Assistance. www.globalissues.org

Smith, J. S., Loder, R. J., Xiquin, S., \& Adela-Garcia, A. (2016). How a Strong Sense of Community Led to Improvements in Rural Health Care: The Case of Patanatic, Guatemala. Journal of International Development, 28, 631-639.

UN (United Nations). (2014a). United Nations Millennium Development Goals. http://www.un.org/millenniumgoals/

UN (United Nations). (2014b). World Urbanization Prospects. https://esa.un.org/unpd/wup/Publications/Files/WUP2014-Highlights.pdf

UN (United Nations). (2015). Transforming Our World: The 2013 Agenda for Sustainable Development. http://www.un.org/ga/search/view_doc.asp?symbol=A/RES/70/1\&Lang=E

World Bank. (2016). Urban Poverty: An Overview. http://web.worldbank.org/WBSITE/EXTERNAL/TOPICS/EXTURBANDEVELOPMENT/EXT URBANPOVERTY/0,,contentMDK:20227679 menuPK:7173704 pagePK:148956 piPK:21661 8 theSitePK:341325,00.html

Submit or recommend next manuscript to SCIRP and we will provide best service for you:

Accepting pre-submission inquiries through Email, Facebook, LinkedIn, Twitter, etc. A wide selection of journals (inclusive of 9 subjects, more than 200 journals)

Providing 24-hour high-quality service

User-friendly online submission system

Fair and swift peer-review system

Efficient typesetting and proofreading procedure

Display of the result of downloads and visits, as well as the number of cited articles Maximum dissemination of your research work

Submit your manuscript at: http://papersubmission.scirp.org/ 